\title{
Autism and Panpsychism: Putting process in mind
}

\author{
Jonathan Delafield-Butt ${ }^{1}$ \\ 1. Laboratory for Innovation in Autism, University of Strathclyde, 50 George Street, Glasgow G1 1QE, \\ Scotland, United Kingdom. email. jonathan.delafield-butt@strath.ac.uk
}

\author{
PREPRINT \\ For publication in \\ Journal of Consciousness Studies \\ Special Issue on Panpsychism and Galileo's Error \\ Edited by Phillip Goff \\ Please see https://www.imprint.co.uk/product/jcs/ \\ for the full copy edited version.
}

\begin{abstract}
Panpsychism is a metaphysical framework around which science can understand the nature of subjective experience. Panpsychism affords a scientific view of mind and body as a coherent mind-body unity, with agentive purpose. Fundamental to minds is motor control, a core aspect that combines sensory experience, its evaluation in choice of agent action, and extension into the public expression of intentional movement. This primary mind-body process appears disturbed in autistic individuals. Empirical analysis of the spatiotemporal properties of intentional movement in autism shows a disruption to the efficient prospective integration and control of movement, a core aspect of mind. This paper examines the capacity of a panpsychist metaphysic to explain mind as fundamentally constituted by units of mindbody sensorimotor agency, which can be understood as the basic building blocks of embodied experience. The implications of a post-Cartesian metaphysic in scientific understanding of minds allows for deeper consideration of the role of movement in subjective experience, and its disturbance in autism as a disturbance to the organization of conscious sensorimotor experience and agency. It's impact on modes of cognition and neural substrates is discussed.
\end{abstract}

Keywords. autism, mind, process, embodiment, sensorimotor agency, consciousness 


\section{Autism and Panpsychism: Putting process in mind}

\section{Autism and Panpsychism}

Panpsychism and autism may seem unexpected bedfellows, but autism is fundamentally a condition of disturbance of subjective experience and panpsychism is a metaphysical framework around which science can better analyse and understand the structure of subjective experience, of mind. Panpsychism affords a view of the 'mind-body duality' as instead a combined 'mind-body singularity', a monad. By doing so, panpsychism may afford a deeper view of the structure of the mind-body relationship than what the conventional vision of a mind and a body - a split Cartesian mind-body duality - can.

Panpsychism has been neglected over the $20^{\text {th }}$ Century as its main metaphysical competitor, materialism, made exceptional gains in powering scientific understanding, and because the idea of 'mind everywhere' seems on the surface of it to be simply untrue. But logical argument suggests panpsychism must be true (Basile, 2010; Strawson, 2006, 2017). More recently in the $21^{\text {st }}$ Century, the limits of materialism to explain conscious experience and to serve as a useful explanatory framework for the psychological sciences, especially in mental health, are drawing in. Panpsychism is now enjoying a resurgence as a favoured solution to the 'hard problem' of consciousness (Chalmers, 1995; Goff, 2019), which is ultimately at the root of our scientific explanations of mind. Panpsychism is also finding new explanatory use in biology as mounting evidence of a fundamental agency operative in many simple, nonhuman and even non-neural organisms comes to the foreground (Calvo, Gagliano, Souza, \& Trewavas, 2019; Delafield-Butt, 2007, 2008; Delafield-Butt, Pepping, Mccaig, \& Lee, 2012; Trewavas, Baluška, Mancuso, \& Calvo, 2020).

For our purposes here, one of panpsychism's most useful features is identification and characterisation of fundamental mind-body singularities known as 'monads' or 'actual occasions', following two of the great panpsychist philosophers from the $18^{\text {th }}$ and $20^{\text {th }}$ Centuries, Leibniz (1716) and Whitehead (1929), respectively. Panpsychism is not a flat theory of an omnipresent, simple and ubiquitous mind that is everywhere. Rather, panpsychism is fundamentally a process metaphysic deeply structured by an ontology of units.

\section{The ontological unit, an actual occasion}

These fundamental 'mind-matter' units in Leibniz and Whitehead's ontology are thought to be invariant no matter their scale or complexity. Whitehead (1929) spent some considerable time describing them, borrowing from the contemporary biology and physics of his day. He named these units 'actual occasions' or 'organisms', each one alive with sentience, its own subjectivity, agency, and purpose. He reasoned each one 'lives' only for a finite period before it 'dies', the effects of its life appropriated into many other occasions, or organisms, touched during its life. These 'occasions' are the 'fundamental drops of experience', they are 'what there is' in nature - mind-body events. 
The aim of this paper is to bring this philosophical framework to bear on autistic experience and scientific understanding of autism. It follows the assertion that panpsychism can afford new thinking in examination of experience useful for empirical scientific advance (DelafieldButt, 2007, 2008). Science can benefit if it can take "consciousness... as an epistemological starting point on par with the epistemological starting points we get from observation and experiment" (Goff, 2019, p. 173). Here, we take as our starting point the metaphysical assertion of panpsychism as a process ontology, bringing it together with first person accounts of autistic experience, empirical data from autism research and motor control psychology, and with theoretical gains in affective neuroscience, embodied cognition, and autism research. In this way, we will map a fundamental mind-matter ontology (metaphysics) onto empirical data from autistic subjective experience $\left(1^{\text {st }}\right.$ person) and experimental data on its physical manifestation ( $3^{\text {rd }}$ person).

\section{Movement in mind}

Fundamental to this repositioning of perspective is motor control, and the psychological nature of animated action. Animal action is always prospectively organised, organised with an eye to the future (Lee, 2000; Von Hofsten, 1993). Each motor impulse generates forces of inertia and momentum that must be known and compensated for ahead of time. Each action is coherent and unified to achieve its efficient purpose, its goal (Bernstein, 1967; Trevarthen, 1984). Additional goals, ideas, aspirations and ambitions may be woven into that singular moment, that singular goal, but in the moment, there is only one direction, one purpose, one goal embodied in the actions of the agent, with mind and body operating as a cohesive and singular entity.

We now understand autism to be a disruption to the efficient integration and control of movement subserving this singular, embodied purpose. Empirical evidence collected over two decades of sensitive motion capture studies shows a subtle, but significant autistic disturbance to intentional body movement (Anzulewicz, Sobota, \& Delafield-Butt, 2016; Casartelli et al., 2020; Cook, Blakemore, \& Press, 2013; Glazebrook, Elliott, \& Lyons, 2006; Mari, Castiello, Marks, Marraffa, \& Prior, 2003; Schmitz, Martineau, Barthélémy, \& Assaiante, 2003; Torres et al., 2013). The evidence suggests this motor disturbance underpins the disorder altogether, and that this motor aspect of autism ought to be considered a core clinical feature of the disorder (Fournier, Hass, Naik, Lodha, \& Cauraugh, 2010; Trevarthen \& Delafield-Butt, 2013a). Purposive movement is the most fundamental aspect of mind lived and experienced in a body (Sheets-Johnstone, 2011). And it is clear its efficient action is disrupted in autism.

Movement normally initiates toward a goal, proceeds toward that goal with small, subtle corrective adjustments until the goal is reached, and successfully acquired. In autism, these small corrective manoeuvres are larger, both increasing and decreasing accelerative forces with exaggerated under- and over-compensations. Because purposeful movement occurs very quickly, usually under one second, these small corrections are not noticeable by the human eye, but they are evident using high-precision motion capture with subsecond kinematic analysis. And they tell us that in ASD, it is as if the trajectory of the movement is always a surprise to the system, that it is forced to constantly monitor and correct its trajectory (Torres et al., 2013). This means that at a fundamental level, sensing and engaging 
the environment in small, purposeful acts is disturbed (Brincker \& Torres, 2013; Whyatt \& Craig, 2013).

This 'autism motor signature' (Anzulewicz et al., 2016; Parma \& De Marchena, 2016) is characterised by a velocity and acceleration-deceleration profile that is regularly adjusted with an increase in velocity at the end of a movement when normally it would reduce to a near-zero at its goal. From a traditional cognitive perspective, this simply implies a functional error in motor execution with disturbance to the sensory processing monitoring it. In this standard paradigm, conscious experience is not thought to be entwined with simple motor control, but as something above it that instructs a motor command to deliver an automated, non-conscious execution of a motor program. In contrast, panpsychism aligns with an embodied and ecological psychology that recognises action as fundamental to psychological construction, and the composition of consciousness (Reed, 1996; Trevarthen and DelafieldButt, 2017).

If we follow this idea that 'fundamental drops' of mind-matter experience are the ontological units on which experience is built, we can see how simple action units can begin to compose the more complex conscious experiences of normal adult life. These units ought to become an important, central unit of analysis for understanding the psychophysical composition of any particular organism of study, too, offering a deeper perspective on experience as embodied and enactive (Gangopadhyay \& Kiverstein, 2009; Stewart, Gapenne, \& Di Paolo, 2011; Varela, Thompson, \& Rosch, 1991). It can take theory of the role of the body in mind further than even the very welcome gains of embodiment in cognitive science and in enactivism (De Jaegher \& Di Paolo, 2007), especially for autism research (De Jaegher, 2013; Grohmann, 2017; Roberts, Krueger, \& Glackin, 2019). Panpsychism deepens the shift in emphasis advanced by the extended, enactive, embodied and emotional view of mind (Clark, 2008; Newen, Bruin, \& Gallagher, 2018), into a richer embodiment of lived experience, structured by a nested ontology of moments, or occasions, of experience.

\section{The Ontological Unit of Purposeful Agent Action}

Panpsychism teaches us that the apparent continuous stream of experience is actually composed of discreet elements of experience that have a particular regular and lawful form of process within them. These mind-body elements incorporate the dual aspect of our experience, with its private mental side and public physical side, into a singular element, or occasion. This is the ontological unit that Whitehead defined at length in his technical opus, Process and Reality (Whitehead, 1929).

\section{Goal-directedness in mind}

Whitehead's 'actual occasion' is defined as the critical element in his 'philosophy of organism' (Whitehead, 1929). It explains goal-directed processes as ontological universals, prehending and acting to achieve an intended future, a subjective aim. Whitehead's ontological unit senses, integrates, and acts. It is very similar, if not identical, to what psychology identifies as a goal-directed action (Delafield-Butt, 2014). The juxtaposition of the ontological unit and goal-directed action defines more precisely how embodied subjective experience can be composed by complexes of discreet actions of the body in everyday life. 
Each goal-directed action obtains data in the specious present for a prospective purpose. These units integrate and re-integrate new data into a single act to achieve a goal, guided by the subject's aim, the intention of the agent determines the course of the integration and the act. These units are individually discreet and serve as building blocks on which more complex experience can be built. In practice these mind-matter building blocks are interwoven to form 'fluid', coherent wholes. They can be serially organized and nested within more complex, farreaching projects to serve ambitions for a distal future. For example, reaching to grasp a cup of coffee may flow fluidly into a next step, a next occasion, of drawing it up to the mouth for drinking. Such serially organized action can become integrated and chained together to serve greater, more spatiotemporally distal goals, such as energising oneself in the moment to do well in an exam in ten minutes, that will altogether serve an ambition for a degree in the future (Delafield-Butt \& Gangopadhyay, 2013; Pezzulo \& Castelfranchi, 2009). Each atomic piece nests together to present actions and their experience as continuous and flowing (Whitehead 1929, p317).

\section{Actions units are mind-matter units}

Each unit is a "fundamental drop of experience" (Whitehead 1929, p28), both matter and mind together. Each action unit involves a mental pole, which is the perceptual and intentional part, together with a physical pole, which is the acting out of the subject into the material of action. Experience as we know it, according to Whitehead, is a society of these actual occasions, one succeeding the next and inter-relating with others. By understanding this unit as an 'atom' of experience, we place ourselves in a better position to understand how this part contributes to the integrated experience of the whole person.

For a more detailed description of the ontological unit in relation to sensorimotor control, see Delafield-Butt (2014).

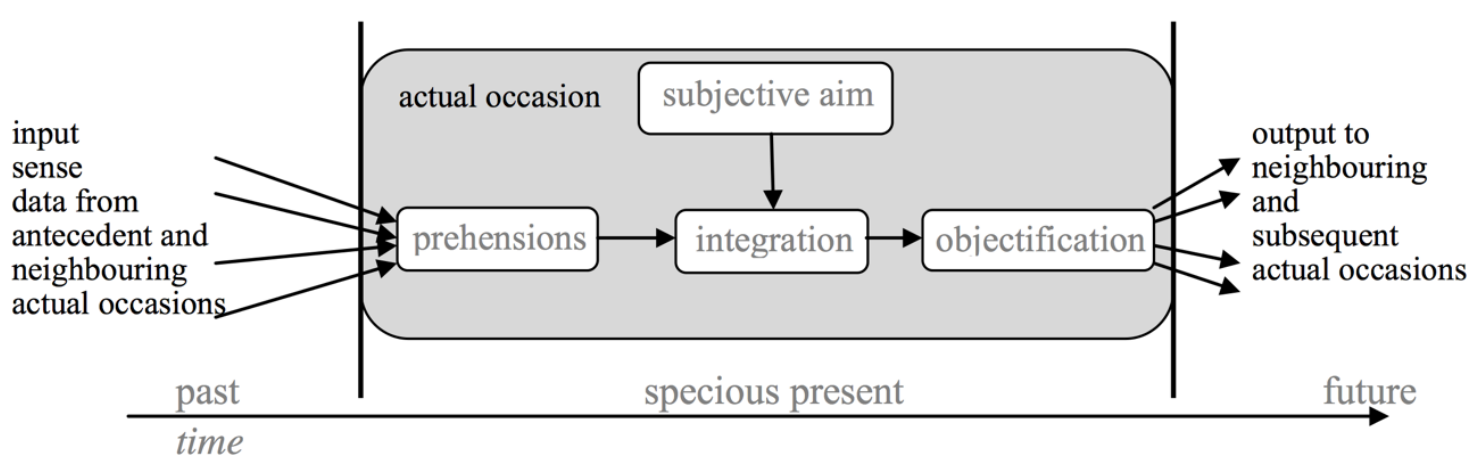

Figure 1. Schematic of the ontological unit. Sense data is prehended and integrated until satisfaction is reached, guided by the subjective aim. The final act of the unit is an objectification of itself into neighbouring and subsequent actual occasions. The comparable components between the ontological unit and a unit of action are, respectively, (i) prehending and sensing, (ii) integrating and also integrating, or comparing, (iii) subjective aim and goal, and (iv) objectification and goal acquisition. In both cases, successful acquisition of the aim of the unit yields satisfaction, the aim being 
reached, and the unit perishes, it's effects now a part of the foundation for future events. Adapted from Delafield-Butt (2014).

\section{Autistic Disturbance to Ontological Units of Agent Action}

According to the system set out above, every unit of experience requires a goal, a subjective aim. But in autism, that goal can be unclear, with an uncertain path from the present moment to the goal. This makes the present moment also unclear, and uncertain. Adjacent events, such as sounds from passing cars or questions from social partners, are perceived, but may not be readily subsumed into the present moment to make integrated sense of it. Autistic disruption to the ontological unit can be characterised by disruption to the subsecond-bysubsecond prospective integration of the senses and adaptive adjustment of motor impulses to serve the immediate subjective aim, or purpose of the act in movement.

Conscious perceptions and their integration in time to serve the purpose of the present moment may be thwarted. The senses of the outside world through vision, hearing, smell, or touch may be heighted, de-contextualised, and surprising (Bogdashina, 2003; Feldman et al., 2018; Jones et al., 2009; Robertson \& Simmons, 2015). Or in other cases they may be attenuated and imperceptible (Ben-Sasson et al., 2009). The same is true of perception of the body's vital states (Trevisan, Parker, \& Mcpartland, 2021), and probably also of the proprioceptive system that monitors the body-in-movement through direct sense of the skeletomusculature (Torres et al., 2013; Torres \& Denisova, 2016). In each of these cases, perception of events appears to lack context, they are not integrated into the occasion at hand, and so can be felt as surprising or hostile, or missed altogether. Surprises overstimulate a sensitive and volatile arousal system, leading to emotional reactions (Delafield-Butt, Dunbar, \& Trevarthen, 2021). This de-contextualised, unintegrated autistic perception and capacity for adaptive response can become overwhelming, destabilizing the integrative and purposeful fluidity of the moment as it seeks satisfaction in adaptive, integrative action.

One result of this disturbance to the present moment may be a compensatory proximal spatiotemporal focus, i.e. a focus that is closer to the present moment, allowing that moment to be understood and controlled, both in mind and in body. This proximal focus can be seen in the stereotypes common in some children with autism, such as hand flapping. The regular, repetitive nature of it produces a degree of coherence within contiguous actions, a flap forward and flap back. By keeping each unit, each flap, contiguous with the other, the action runs continuously seamlessly in a known, predictable manner. This can give a sense of coherence, certainty, and calm.

Such proximal focus has advantages and disadvantages. On the negative side, it can mean restricted interests early in life that thwart learning about the varieties of experiences possible in the world, and this can compromise development and learning. It can also disrupt intra-personal coherence of basic states of being as moving-with-feeling in self-awareness, affecting internal subjective coherence of consciousness, and challenging one's capacity to self-regulate arousal and interest, especially in communication with others (Delafield-Butt et 
al., 2021). And on the positive side, it's temporal discontinuity with a typical linear sense of time can present new modes of thought that allow special intelligences to develop.

\section{Modes of Thought in Autism}

Temporal extension is what child psychologist Margaret Donaldson (1992) called the 'line mode' of thought. It is made in active participation through events in time that themselves are structured with an aim, or purpose (Delafield-Butt \& Trevarthen, 2013; Trevarthen \& Delafield-Butt, 2013b). And although apparently continuous and fluid, each of life's daily tasks itself presents as a discreet unit, and is composed of units (Delafield-Butt, 2018). For example, in my case getting out of bed requires knowing where the coffee is and the state of readiness of the stove-top machine, then the action of moving out of bed, opening the bedroom door, walking through the corridor (quietly, so as not to disturb the children), navigating the cats (also anticipating the kitchen routine), then preparing the machine and coffee for making coffee, and food for the cats. This whole effort is organised to achieve a goal - a cup of coffee - which itself is the first step in starting my day, which itself will be composed of similar projects: breakfast, readying the children for school, working on a paper, teaching a class, attending meetings, each meeting of which is step along a protracted, multiperson social project with a goal of its own, and to which I contribute my conscious intelligence, energy and skills. All of this is extensive and organised in 'future' time. Its actions organised to serve the future goals of the subject in action in the present moment.

In autism, this line mode of thought and the plans that it enables is disturbed (Delafield-Butt \& Gangopadhyay, 2013; Trevarthen \& Delafield-Butt, 2013a). But it is not only thought that is disturbed, it is the basic element of consciousness on which thought rests that is disturbed. The morning ritual of coffee proceeds linearly from bed to the kitchen to the coffee-making, and its final, beautiful result. As a neurotypical person, the coffee is in mind from the beginning, and each step along the way falls in naturally to be bring me from my present moment without coffee, informed and structured by implicit knowledge of the steps required to get there, how they can be carried out, and approximately how each step will feel, to bring me to the goal efficiently. This future-oriented organisation of knowledge that structures conscious experience of a living person in a body and that occupies and navigates spacetime is not organised with the same cohesive, prospective, and linear manner in autism. Rather, all things may come at once.

As a result, memories of experiences may not be contextualised into a line extensive in time, but as discreet events de-contextualised and available as objects. The self-identifying Asperger's entrepreneur Elon Musk describes his mental 'vector space' with ready access to a store of memories at any one moment (Musk, 2021). This is not dissimilar to the experience of Naoki Higashida (2007), a non-verbal autistic boy who describes his lack of experience of time,

“Inside my head there really isn't such a big difference between what I was told just now, and what I heard a long, long time ago. So, I do understand things, but my way of remembering them works differently from everyone else's. I imagine 
a normal person's memory is arranged continuously like a line. My memory, however, is more like a pool of dots." (p23-24)

Naoki's pool of dots, although hard to contextualise into the present moment with its particular goal in mind, nevertheless can allow for powerful abstract knowledge without the restrictions of lived linearity.

The same disruption found at the level of subsecond prospective action may be present up and down the levels of organisation of agent action. Fragmentation of normal linear sequences into discreet features is observable down the scale with observation of perceptual incoherence identified under the Weak Central Coherence hypothesis (Happé \& Frith, 2006). Weak central coherence may be one manifestation of a more fundamental, core issue of ontological integration.

The same ontological characteristics appears to radiate up levels of action organisation in autism, keeping the same form. For example, a large project spanning many tens of minutes, such as walking to the swimming pool for a swim, may present as a project with many uncertainties. Each step in the process, preparing one's clothes for the pool, leaving the house, walking down the street, making each change of direction appropriately while walking to arrive at the pool, entering the styles, changing, and entering the water, can be presented in autism at the start of the project as a cacophony of individual elements without sequence, leaving the individual uncertain of how each step can be put together linearly in time. This uncertainty creates anxieties, elevates arousal, and generates resistance to start the project altogether. The parallel with a single act of movement, reaching-to-grasp, for example, is clear. Each project, reach-to-grasp or walk-to-pool, presents a linear sequence of coordinated actions that must be known and performed at a suitable moment in time-over many tens of milliseconds in the case of reaching-to-grasp, and over many tens of minutes in the case of walking to the pool. Thus, disruption to the ontological structure appears the same, irrespective of its spatiotemporal scale.

In this way, conscious experience itself is different in autism from neurotypical individuals. And although autism is not considered a clinical disorder of consciousness (American Psychiatric Association, 2013; World Health Organisation, 2019), conscious content becomes differently organised and conscious experience altered.

\section{Conclusions}

Understanding the mind-body relation from the position of panpsychism lends a different structure with which to frame, analyse, and understand embodied experience. That frame allows empirical analysis of mind-body data as subsecond kinematics of goal-directed action to be interpreted vis-à-vis subjective experience. Without this framework, the structure of embodied experience and the role of sensorimotor goal-directedness as fundamental to it can be missed. Instead, one may be left with a flat, mechanical framework that views mind as a machine, presenting specialised modules for awareness, planning, and execution of motor programs. The deterministic model may make good sense of the same empirical data, 
but it also leads discovery into its own pre-determined areas of interest in cortically-mediated modules, each of which is without conscious experience on its own.

Panpsychism, on the other hand, casts a different light on the matter altogether, one where mind, purpose, and consciousness are present at all levels of the living organism. Defining these levels, how they structure experience, and how they may be disrupted in cases of psychopathology such as autism, is the work of good science to follow, with exactly the same empirical and experimental basis as what has come before, but with new direction and a deeper sense of the role of agency in psychological organisation and health.

This revision of our metaphysical assumptions may ultimately help to identify the neuropsychological systems that compose mind-body units of conscious experience, with a deeper appreciation of brainstem integrations of neuromotor control and affective evaluations as a source of primary conscious experience (Damásio, 2010; Panksepp \& Biven, 2012; Solms, 2021; Solms \& Panksepp, 2012; Vandekerckhove \& Panksepp, 2009; Vandekerckhove and Panksepp, 2011). We are beginning to understand brainstem-mediated primary consciousness, responsible for the sensorimotor integrations in skilled action, and its affective evaluation, is disrupted in autism from early life (Bosco et al., 2019; Dadalko and Travers, 2018; Delafield-Butt et al., 2021). This is an area ripe for investigation, informed by a deeper understanding of the metaphysics of embodiment, and how it may be organised in autism.

\section{Acknowledgements}

I am grateful to Penelope Dunbar for extensive discussion and insight into autism. And to Pauline Phemister, the late Wendy Wheeler, and the RSE Organisms and Their Choices group for discussion of panpsychism and agency in nature, and especially also to Ross Stein and Pierfrancesco Basile on Whitehead in earlier, lengthy discussion and to whom I have never properly thanked. Finally, to Philip Goff who has reinvigorated panpsychism and its importance to science. 


\section{References}

American Psychiatric Association. (2013). Diagnostic and Statistical Manual of Mental Disorders (DSM-5) (5th ed.). Washington, DC: American Psychiatric Association.

Anzulewicz, A., Sobota, K., \& Delafield-Butt, J. T. (2016). Toward the autism motor signature: Gesture patterns during smart tablet gameplay identify children with autism. Scientific Reports, 6.

Basile, P. (2010). It must be true - but how can it be? Some remarks on panpsychism and mental composition. In P. Basile, J. Kiverstein \& P. Phemister (Eds.), The Metaphysics of Consciousness (pp. 93-112). Cambridge: Cambridge University Press.

Ben-Sasson, A., Hen, L., Fluss, R., Cermak, S. A., Engel-Yeger, B., \& Gal, E. (2009). A metaanalysis of sensory modulation symptoms in individuals with autism spectrum disorders. J Autism Dev Disord, 39(1), 1-11.

Bernstein, N. A. (1967). The Co-ordination and Regulation of Movements. Oxford: Pergamon Press.

Bogdashina, O. (2003). Sensory Perceptual Issues in Autism and Aspergers Syndrome: Different Sensory Experiences, Different Perceptual Worlds. . London: Jessica Kingsley Publishers.

Brincker, M., \& Torres, E. (2013). Noise from the periphery in autism. Frontiers in Integrative Neuroscience, 7(34).

Calvo, P., Gagliano, M., Souza, G. M., \& Trewavas, A. (2019). Plants are intelligent, here's how. Annals of Botany, 125(1), 11-28.

Casartelli, L., Cesareo, A., Biffi, E., Campione, G. C., Villa, L., Molteni, M., et al. (2020). Vitality form expression in autism. Scientific Reports, 10(1), 17182.

Chalmers, D. J. (1995). Facing Up to the Problem of Consciousness. Journal of Consciousness Studies, 2, 200-219.

Clark, A. (2008). Supersizing the Mind: Embodiment, Action, and Cognitive Extension. Oxford: Oxford University Press.

Cook, J. L., Blakemore, S. J., \& Press, C. (2013). Atypical basic movement kinematics in autism spectrum conditions. Brain, 136(Pt 9), 2816-2824.

Damásio, A. (2010). Self Comes to Mind: Constructing the conscious brain.: Pantheon Books.

De Jaegher, H. (2013). Embodiment and sense-making in autism. Frontiers in Integrative Neuroscience, 7.

De Jaegher, H., \& Di Paolo, E. (2007). Participatory sense-making. Phenomenology and the Cognitive Sciences, 6, 485-507.

Delafield-Butt, J. (2018). The Emotional and Embodied Nature of Human Understanding: Sharing narratives of meaning. In C. Trevarthen, J. Delafield-Butt \& A.-W. Dunlop (Eds.), The Child's Curriculum: Working with the natural voices of young children. Oxford: Oxford University Press.

Delafield-Butt, J., Dunbar, P., \& Trevarthen, C. (2021). Disruption to Embodiment in Autism, and Its Repair. In N. Papaneophytou \& U. Das (Eds.), Emerging Programs for Autism Spectrum Disorder: Elsevier Academic Press.

Delafield-Butt, J. T. (2007). Towards a process ontology of organism: Explaining behaviour in a cell. In T. Kelly \& M. Dibben (Eds.), Applied Process Thought: Frontiers of Theory and Research. Paris: Ontos Verlag.

Delafield-Butt, J. T. (2008). Biology. In M. Weber, J. Seibt \& N. Rescher (Eds.), Handbook of Whiteheadian Process Thought. Paris: Ontos Verlag. 
Delafield-Butt, J. T. (2014). Process and Action: Whitehead's Ontological Units and Perceptuomotor Control Units. In S. Koutroufinis (Ed.), Life and Process (pp. 133-156). Berlin/Boston: De Gruyter Ontos.

Delafield-Butt, J. T., \& Gangopadhyay, N. (2013). Sensorimotor intentionality: The origins of intentionality in prospective agent action. Developmental Review, 33(4), 399-425.

Delafield-Butt, J. T., Pepping, G.-J., McCaig, C. D., \& Lee, D. N. (2012). Prospective guidance in a free-swimming cell. Biological Cybernetics, 106, 283-293.

Delafield-Butt, J. T., \& Trevarthen, C. (2013). Theories of the development of human communication. In P. Cobley \& P. Schultz (Eds.), Theories and Models of Communication (pp. 199-222). Berlin/Boston: De Gruyter Mouton.

Donaldson, M. (1992). Human Minds: An exploration. London: Allen Lane.

Feldman, J. I., Dunham, K., Cassidy, M., Wallace, M. T., Liu, Y., \& Woynaroski, T. G. (2018). Audiovisual multisensory integration in individuals with autism spectrum disorder: $\mathrm{A}$ systematic review and meta-analysis. Neurosci Biobehav Rev, 95, 220-234.

Fournier, K. A., Hass, C. J., Naik, S. K., Lodha, N., \& Cauraugh, J. H. (2010). Motor coordination in autism spectrum disorders: a synthesis and meta-analysis. J Autism Dev Disord, 40(10), 1227-1240.

Gangopadhyay, N., \& Kiverstein, J. (2009). Enactivism and the Unity of Perception and Action. Topoi-an International Review of Philosophy, 28(1), 63-73.

Glazebrook, C. M., Elliott, D., \& Lyons, J. (2006). A kinematic analysis of how young adults with and without autism plan and control goal-directed movements. Motor Control, 10(3), 244-264.

Goff, P. (2019). Galileo's Error: Foundations for a new science of consciousness. New York: Pantheon Books.

Grohmann, T. D. A. (2017). A Phenomenological Account of Sensorimotor Difficulties in Autism: Intentionality, Movement, and Proprioception. Psychopathology, 50(6), 408415.

Happé, F., \& Frith, U. (2006). The Weak Coherence Account: Detail-focused Cognitive Style in Autism Spectrum Disorders. Journal of Autism and Developmental Disorders, 36(1), 5-25.

Higashida, N. (2007). The Reason I Jump. London: Hodder \& Stoughton.

Jones, C. R. G., Happé, F., Baird, G., Simonoff, E., Marsden, A. J. S., Tregay, J., et al. (2009). Auditory discrimination and auditory sensory behaviours in autism spectrum disorders. Neuropsychologia, 47, 2850-2858.

Lee, D. N. (2000). Prospective guidance of movement. International Journal of Psychology, 35(3-4), 186-186.

Leibniz, G. (1716). La Monadologie.

Mari, M., Castiello, U., Marks, D., Marraffa, C., \& Prior, M. (2003). The reach-to-grasp movement in children with autism spectrum disorder. Philosophical Transactions of the Royal Society B -Biological Sciences, 358, 393-403.

Musk, E. (2021). Interview on Youtube. In https://www.youtube.com/watch?v=vXuWbPRgflg (Ed.)).

Newen, A., Bruin, L. D., \& Gallagher, S. (Eds.). (2018). The Oxford Handbook of 4 E Cognition. Oxford: Oxford University Press.

Panksepp, J., \& Biven, L. (2012). The Archaeology of Mind: Neuroevolutionary Origins of Human Emotions. New York: Norton. 
Parma, V., \& de Marchena, A. B. (2016). Motor signatures in autism spectrum disorder: the importance of variability. J Neurophysiol, 115(3), 1081-1084.

Pezzulo, G., \& Castelfranchi, C. (2009). Thinking as the control of imagination: a conceptual framework for goal-directed systems. Psychological Research, 73, 559-577.

Roberts, T., Krueger, J., \& Glackin, S. (2019). Psychiatry Beyond the Brain; Externalism, Mental Health, and Autistic Spectrum Disorder. Philosophy, Psychiatry \& Psychology, 26, E-51.

Robertson, A., \& Simmons, D. (2015). The Sensory Experiences of Adults with Autism Spectrum Disorder: A Qualitative Analysis. Perception, 44, 569 - 586.

Schmitz, C., Martineau, J., Barthélémy, C., \& Assaiante, C. (2003). Motor control and children with autism: deficit of anticipatory function? Neuroscience Letters, 348, 17-20.

Sheets-Johnstone, M. (2011). The Primacy of Movement (2nd ed.). New York: John Benjamins.

Solms, M. (2021). The Hidden Spring: A Journey to the Source of Consciousness. London: Profile Books.

Solms, M., \& Panksepp, J. (2012). The "Id" Knows More than the "Ego" Admits: Neuropsychoanalytic and Primal Consciousness Perspectives on the Interface Between Affective and Cognitive Neuroscience. Brain Science, 2, 147-174.

Stewart, J., Gapenne, O., \& Di Paolo, E. (Eds.). (2011). Enaction: Toward a new paradigm for cognitive science. Cambridge, MA: The MIT Press.

Strawson, G. (2006). Realistic monism: Why physicalism entails panpsychism. In A. Freeman (Ed.), Consciousness and Its Place in Nature. (pp. 3-31). Charlottesville, VA: Imprint Academic.

Strawson, G. (2017). Mind and Being: The primacy of panpsychism. In G. Brüntrup \& L. Jaskolla (Eds.), Panpsychism: Contemporary perspectives. Oxford: Oxford University Press.

Torres, E. B., Brincker, M., Isenhower, R. W., Yanovich, P., Stigler, K. A., Nurnberger, J. I., et al. (2013). Autism: The Micro-Movement Perspective. Frontiers in Integrative Neuroscience, 7.

Torres, E. B., \& Denisova, K. (2016). Motor noise is rich signal in autism research and pharmacological treatments. Sci Rep, 6, 37422.

Trevarthen, C. (1984). How control of movement develops. In H. T. A. Whiting (Ed.), Human Motor Actions: Bernstein Reassessed (pp. 223-261). Amsterdam: Elsevier (North Holland).

Trevarthen, C., \& Delafield-Butt, J. T. (2013a). Autism as a developmental disorder in intentional movement and affective engagement. Frontiers in Integrative Neuroscience, 7, 49.

Trevarthen, C., \& Delafield-Butt, J. T. (2013b). Biology of Shared Meaning and Language Development: Regulating the Life of Narratives. In M. Legerstee, D. Haley \& M. Bornstein (Eds.), The Infant Mind: Origins of the Social Brain (pp. 167-199). New York: Guildford Press.

Trevisan, D. A., Parker, T., \& McPartland, J. C. (2021). First-Hand Accounts of Interoceptive Difficulties in Autistic Adults. J Autism Dev Disord.

Trewavas, A., Baluška, F., Mancuso, S., \& Calvo, P. (2020). Consciousness Facilitates Plant Behavior. Trends in Plant Science, 25(3), 216-217.

Vandekerckhove, M., \& Panksepp, J. (2009). The flow of anoetic to noetic and autonoetic consciousness: A vision of unknowing (anoetic) and knowing (noetic) consciousness in 
the remembrance of things past and imagined futures. Consciousness and Cognition, $18,1018-1028$.

Varela, F. J., Thompson, E. T., \& Rosch, E. (1991). The Embodied Mind. Cambridge, MA: MIT Press.

von Hofsten, C. (1993). Prospective Control -- A basic aspect of action development. Human Development, 36, 253-270.

Whitehead, A. N. (1929). Process and Reality. New York: Macmillan.

Whyatt, C., \& Craig, C. (2013). Sensory-motor problems in Autism. Frontiers in Integrative Neuroscience, 7.

World Health Organisation. (2019). International statistical classification of diseases and related health problems (ICD-11) (11 ed.): World Health Organization. 